\title{
Easy-to-build and affordable continuous positive airway pressure CPAP device for adult patients in low-income countries
}

To the Editor:

Continuous positive airway pressure (CPAP) is the treatment of choice for several types of sleep disordered breathing (SDB), of which sleep apnoea is an obvious example. Although precise epidemiological data are scarce, SDB are prevalent in low-income countries (LICs) $[1,2]$. Moreover, given that the risk of SDB is associated with the patient's body mass index, and that the worldwide obesity pandemic involves not only developed countries but also LICs [2,3], it is expected that the incidence of sleep apnoea will continuously increase in LICs, and the need for CPAP devices will accordingly rise. Moreover, the demand for CPAP devices in LICs is also anticipated to increase in light of the few operationally equipped intensive care units in these countries [4]. Indeed, cheap CPAP devices, although with less versatile applications than mechanical ventilators, provide rescue and treatment options that can reduce mortality and intubation rates in some patients [5]. Unfortunately, these options are seldom implemented in LICs since neither patients nor hospitals are able to afford commercial CPAP devices. It is also noteworthy that CPAP devices specifically designed and commercialised in LICs [6], which achieve cost reductions by avoiding optional device features [7], do not offer a realistic therapeutic alternative.

A potentially viable solution that provides affordable healthcare products for patients in LICs is to promote and strengthen local health-industry value chains to improve industrial development [8]. To this effect, cooperation efforts from developed countries must move their focus from philanthropic provision of Western-made products to empowering LIC teams in designing and manufacturing performant devices locally. Whereas this approach would obviously not work in case of medical devices requiring highly complex technology, it is feasible for medical devices based on simple technical principles, such as CPAP [9]. The open-source hardware approach [10], which consists of making the design publicly available for free use, modification and redistribution, is aimed at reducing medical device access gaps, particularly in LICs [11]. Collaborative design thinking and co-creation initiatives [12] reuniting expert teams from developed and developing countries is an efficient way to implement this approach, for instance to provide bubble-CPAP devices for treating acute respiratory failure in preterm birth and pneumonia in infants [13]. In this context, we herein describe our experience of technology transfer collaboration between teams from Europe, the USA and Africa in developing an easy-to-build and affordable CPAP device for adults with $\mathrm{SBD}$, an application requiring a technical solution completely different from bubble-CPAP [13].

Consistent with our general approach, we built a CPAP device using off-the-shelf low-cost components bought using e-commerce. Nasal pressure is generated by a small $(90 \mathrm{~g})$ high-pressure $\left(75 \mathrm{cmH}_{2} \mathrm{O}\right)$ blower (with corresponding driver) specifically commercialised (CE mark) for CPAP devices (WM7040, Ning Bo Feng Hua Wei Cheng Motor Factory, Zhejiang, China). Pressure is measured by a temperaturecompensated transducer (XGZP6847005KPG, 0-50 $\mathrm{cmH}_{2} \mathrm{O}$; CFSensor, Wuhu, Anhui, China) and the blower is controlled by a simple custom-made proportional-integral feedback circuit. An arduinocontrolled LCD-display $(16 \times 2$ characters) shows both the targeted and measured pressures. The minimum generated $\mathrm{CPAP}$ is set at $4 \mathrm{cmH}_{2} \mathrm{O}$ to prevent rebreathing, and maximum nasal pressure is prescribed to a safe value of $20 \mathrm{cmH}_{2} \mathrm{O}$ (by limiting the nominal 24-VDC blower power supply to 12-VDC). The retail cost of all the components including the power (nominal 220-VAC/12-VDC, 60W) source and materials for the electronic board and circuit is approximately EUR 60, a figure that would be reduced in the case of

@ERSpublications

Teams from developed and developing countries have collaborated to design and test a low-cost, highperformance device to apply continuous positive airway pressure for treating patients in low-income countries http://ow.ly/Cllj30nMGQq

Cite this article as: Farré R, Montserrat JM, Solana G, et al. Easy-to-build and affordable continuous positive airway pressure CPAP device for adult patients in low-income countries. Eur Respir J 2019; 53 : 1802290 [https://doi.org/10.1183/13993003.02290-2018]. 
wholesale purchase. All the technical information and detailed circuit schematics required to build this CPAP device (which is readily achievable by any electronics technician or first-year engineering student) are available for release under free terms following the open-source hardware approach (www.ub.edu/ biofisica/dwn/CPAP.pdf).

The performance of this novel CPAP device was evaluated at the bench by connecting it to a piston-pump patient simulator [14] through conventional tubing, including a $5 \mathrm{~mm}$-diameter orifice at the nasal mask to create an intended air leak orifice to avoid rebreathing (minimum washout flow of $20 \mathrm{~L} \cdot \mathrm{min}^{-1}$ at $4 \mathrm{cmH}_{2} \mathrm{O}$ ). The dynamic stability of the nasal pressure provided by the device for different CPAP settings $\left(4,8,12\right.$ and $\left.16 \mathrm{cmH}_{2} \mathrm{O}\right)$ was measured for several simulated patient breathing flows (tidal volume: $0.5 \mathrm{~L}$; 10, 15 and 20 breaths $\mathrm{min}^{-1}$ ) with and without including a simulated unintended air leak (up to $35 \mathrm{~L} \cdot \mathrm{min}^{-1}$ at $\mathrm{CPAP}$ of $16 \mathrm{cmH}_{2} \mathrm{O}$ ) at the mask level to simulate poor fitting to patient's face and/or mouth air leak [15]. For the sake of comparison, the same bench test conditions were also applied to a high-performance commercially available CPAP device (AirSense 10; Resmed, Sydney, Australia). Figure 1 shows the excellent performance of the designed CPAP device even under the most strenuous conditions: CPAP of $16 \mathrm{cmH}_{2} \mathrm{O}$, respiratory rate set at 20 breaths. $\mathrm{min}^{-1}$, and superimposed air leak of $35 \mathrm{~L} \cdot \mathrm{min}^{-1}[14$, 16]. Indeed, pressure fluctuations (peak-to-peak along the breathing cycle) measured with an external transducer at the nasal mask level were very small $\left(0.5 \mathrm{cmH}_{2} \mathrm{O}\right)$ in absence of unintended leaks. Moreover, nasal pressure actually generated by our CPAP device was virtually insensitive to application of a $35 \mathrm{~L} \cdot \mathrm{min}^{-1}$ unintended air leak: mean pressure moved from 16.1 to $15.9 \mathrm{cmH}_{2} \mathrm{O}$ and pressure oscillations minimally increased to $0.8 \mathrm{cmH}_{2} \mathrm{O}$. In fact, the nasal pressure generated by our low-cost prototype was slightly more stable that the one provided by the conventional device which exhibited higher breathinginduced pressure fluctuations and was less stable in response to the $35 \mathrm{~L} \cdot \mathrm{min}^{-1}$ unintended leak (figure 1).

Using the in-house built CPAP device described here in LICs should comply with the existing local regulations on medical devices, taking into account that it has not undergone the high-cost medical device regulatory approval (e.g. US Food and Drug Administration or CE mark) required for clinical use in Western countries. However, it should be mentioned that the approach described herein is not aimed at replacing commercially available CPAP devices, which of course should be used whenever possible. Our proposal for in-house building of CPAP devices like the one proposed here would be totally unnecessary in the ideal circumstances that the huge economic disparities between developed countries, where most of the medical device industry is based, and LICs disappeared, or at least were considerably reduced, thereby reducing the onerous and inaccessible pricing that currently precludes their purchase in LICs. However, it would also be unreasonable to passively wait and leave patients untreated until the world macro-economy changes for the better. Remarkably, approaches such as the current device presented here should not only

FIGURE 1 Pressure measured at the nasal mask of a simulated patient breathing with a tidal volume of $0.5 \mathrm{~L}$ at 20 breaths $\cdot \mathrm{min}^{-1}$ and targeted continuous positive airway pressure of $16 \mathrm{~cm} \mathrm{H}_{2} \mathrm{O}$. When indicated, a $35 \mathrm{~L} \cdot \mathrm{min}^{-1}$ unintended air leak was imposed at the mask level to simulate poor fitting to the patient's face and/or mouth air leak. a) Designed prototype device. Mean pressure and peak-to-peak pressure fluctuations were $16.1 \mathrm{cmH}_{2} \mathrm{O}$ and $0.5 \mathrm{cmH}_{2} \mathrm{O}$ with no unintended leak and $15.9 \mathrm{~cm} \mathrm{H}_{2} \mathrm{O}$ and $0.8 \mathrm{cmH}_{2} \mathrm{O}$ with unintended leak, respectively. b) Commercially available device (AirSense10; ResMed, Sydney, Australia). Mean pressure and peak-to-peak pressure fluctuations were $16.0 \mathrm{cmH}_{2} \mathrm{O}$ and $0.6 \mathrm{cmH}_{2} \mathrm{O}$ with no unintended leak and $16.5 \mathrm{cmH}_{2} \mathrm{O}$ and $1.0 \mathrm{cmH}_{2} \mathrm{O}$ with unintended leak, respectively.
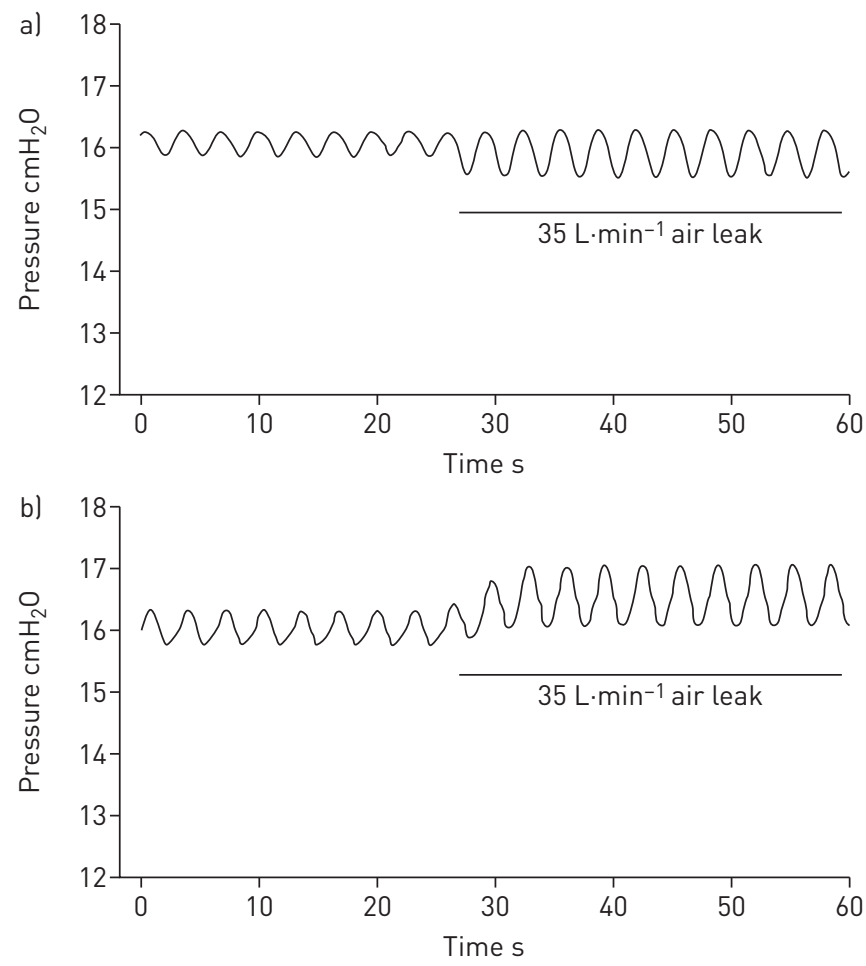
result in readily available CPAP devices, but should also empower clinical, technical and educational teams to implement local industrial projects contributing to economic development $[8,11]$.

In conclusion, under the umbrella of an open-source perspective we designed and tested a high-performance CPAP device for in-house assembly in LIC centres, which is low-cost, easy to build and, most importantly, simple to service technically on site. The described procedure should allow the provision of CPAP treatment to LIC patients who otherwise would not have access to this lifesaving therapy.

Ramon Farré ${ }^{1,2,3}$, Josep M. Montserrat ${ }^{2,3,4}$, Gorka Solana ${ }^{5}$, David Gozal ${ }^{6}$ and Daniel Navajas ${ }^{1,2,7}$

${ }^{1}$ Unitat de Biofísica i Bioenginyeria, Facultat de Medicina i Ciències de la Salut, Universitat de Barcelona, Barcelona, Spain. ${ }^{2}$ CIBER de Enfermedades Respiratorias, Madrid, Spain. ${ }^{3}$ Institut Investigacions Biomediques August Pi Sunyer, Barcelona, Spain. ${ }^{4}$ Sleep Lab, Hospital Clinic-Universitat de Barcelona, Barcelona, Spain. ${ }^{5}$ Escola Superior Técnica, Universidade Pedagógica Maxixe, Maxixe, Mozambique. ${ }^{6}$ Dept of Child Health, University of Missouri School of Medicine, Columbia, MO, USA. ${ }^{7}$ Institut for Bioengineering of Catalonia, The Barcelona Institute of Science and Technology, Barcelona, Spain.

Correspondence: Ramon Farré, Unitat Biofísica i Bioenginyeria, Facultat de Medicina i Ciències de la Salut, Casanova 143, 08036 Barcelona, Spain. E-mail: rfarre@ub.edu

Received: Dec 032018 | Accepted after revision: Jan 222019

Acknowledgements: The authors thank Miguel A. Rodríguez-Lázaro (Universitat de Barcelona, Barcelona, Spain) for his excellent technical support.

Conflict of interest: R. Farre reports other from ResMed (contract between the University of Barcelona and ResMed to bench test CPAP devices) and other from ANTADIR (contract between the University of Barcelona and ANTADIR to bench test CPAP devices), outside the submitted work. J.M. Montserrat has nothing to disclose. G. Solana has nothing to disclose. D. Gozal has nothing to disclose. D. Navajas has nothing to disclose.

Support statement: This work was supported in part by the Spanish Ministry of Economy and Competitiveness (SAF2017-85574-R, DPI2017-83721-P). D. Gozal is supported by National Institutes of Health grants HL130984 and HL140548. Funding information for this article has been deposited with the Crossref Funder Registry.

\section{References}

1 Accinelli RA, Llanos O, López LM, et al. Caregiver perception of sleep-disordered breathing-associated symptoms in children of rural Andean communities above $4000 \mathrm{~m}$ with chronic exposure to biomass fuel. Sleep Med 2015; 16: 723-728.

2 Akanbi MO, Agaba PA, Ozoh OB, et al. Obesity and obstructive sleep apnea risk among Nigerians. J Med Trop 2017; 19: 110-115.

3 Ng M, Fleming T, Robinson $\mathrm{M}$, et al. Global, regional, and national prevalence of overweight and obesity in children and adults during 1980-2013: a systematic analysis for the Global Burden of Disease Study 2013. Lancet 2014; 384: 766-781.

4 Murthy S, Leligdowicz A, Adhikari NK. Intensive care unit capacity in low-income countries: a systematic review. PLoS One 2015; 10: e0116949.

5 Pandor A, Thokala P, Goodacre S, et al. Pre-hospital non-invasive ventilation for acute respiratory failure: a systematic review and cost-effectiveness evaluation. Health Technol Assess 2015; 19: v-vi.

6 WHO. Compendium of Innovative Health Technologies for Low Resource settings, 2011-2014. Assistive devices, eHealth solutions, Medical devices, Other technologies, Technologies for outbreaks. Geneva, World Health Organization, 2015. Available from: www.who.int/medical_devices/innovation/compendium/en/

7 DePasse JW, Caldwell A, Santorino D, et al. Affordable medical technologies: bringing Value-Based Design into global health. BMJ Innovations 2016; 2: 4-7.

8 Mackintosh M, Tibandebage P, Karimi Njeru M, et al. Rethinking health sector procurement as developmental linkages in East Africa. Soc Sci Med 2018; 200: 182-189.

9 Sullivan CE, Issa FG, Berthon-Jones M, et al. Reversal of obstructive sleep apnoea by continuous positive airway pressure applied through the nares. Lancet 1981; 1: 862-865.

10 Niezen G, Eslambolchilar P, Thimbleby H. Open-source hardware for medical devices. BMJ Innov 2016; 2: 78-83.

11 De Maria C, Mazzei D, Ahluwalia A. Open source biomedical engineering for sustainability in African healthcare: combining academic excellence with innovation. Proceedings of the ICDS 2014, The Eighth International Conference on Digital Society; 2014 Mar 23-27, Barcelona, Spain; pp. 48-53. Available from: www.thinkmind.org/ index.php?view=article\&articleid=icds_2014_2_40_10173

12 Clifford KL, Zaman MH. Engineering, global health, and inclusive innovation: focus on partnership, system strengthening, and local impact for SDGs. Glob Health Action 2016; 9: 30175.

13 Farré R, Trias G, Solana G, et al. Novel approach for providing pediatric continuous positive airway pressure (CPAP) devices in low-income underesourced regions. Am J Respir Crit Care Med 2019; 199: 118-120.

14 Farré R, Montserrat JM, Rigau J, et al. Response of automatic continuous positive airway pressure devices to different sleep breathing patterns: a bench study. Am J Respir Crit Care Med 2002; 166: 469-473.

15 Association for Respiratory Technology and Physiology. Standards of Care - CPAP Devices (Technical and Performance). www.artp.org.uk/en/utilities/all-publications.cfm/Sleep_SOC_CPAP_Devices_TechandPerformance Date last accessed December 2, 2018. Date last updated: July 112018.

16 Lebret M, Martinot JB, Arnol N, et al. Factors contributing to unintentional leak during CPAP treatment: a systematic review. Chest 2017; 151: 707-719. 